\title{
A Produção Mais Limpa como Geradora de Inovação e Competitividade
}

\author{
Ângela Denise Lemos \\ Luis Felipe Nascimento
}

\section{RESUMO}

Este artigo tem por origem uma dissertação de mestrado em administração. Seu objetivo é divulgar resultados referentes à adoção de estratégias de Produção Mais Limpa (PML), como forma de começar a adequar-se aos novos padrões de produtos saudáveis e limpos, exigidos pelo mercado consumidor, e que culminaram com a geração de inovações e de competitividade para a empresa. O método de pesquisa utilizado foi o estudo de caso. A empresa pesquisada foi a Fazenda Cerro do Tigre (FCT), de Alegrete, RS, Brasil, produtora de arroz irrigado. Os resultados indicam que a empresa, quando começa a preocupar-se com as questões ambientais e adota estratégias de Produção Mais Limpa, começa a usufruir de um processo de melhoria contínua, que propicia o surgimento de inovações em todos os sentidos (processo, produto e gerência). A principal conclusão é que a PML facilita o surgimento de inovações e que estas inovações facilitam o alcance da competitividade.

Palavras-chaves: produção mais limpa; inovação; competitividade; questões ambientais; agronegócio.

\section{Abstract}

This paper results from a research for a Master in Business Administration dissertation. Its objective is to disclose results related with the adoption of strategies of Cleaner Production (CP), as a manner of beginning to adapt agronomical activity to new patterns of healthy and cleaner products, demanded by the consuming market, and that culminated with the generation of innovations and competitiveness for the firm. The research method was the case study. The research was made in a farm called Fazenda Cerro do Tigre (FCT), located in Alegrete, RS, Brazil, which deals with the irrigated rice cropping. The results indicate that when the firm begins to concern about the environmental issues and adopts strategies of Cleaner Production, it begins to make good use of a continuous improvement process, which propitiates the appearance of innovations in all segments (process, product and management). As an import conclusion, it is possible to say that the $\mathrm{CP}$ adoption facilitates the generation of innovations. The innovations, by their turn, facilitate the attainment of the competitiveness.

Key words: cleaner production; innovation; competitiveness; environmental issues; agribusiness. 


\section{INTRODUÇÃO}

O mundo está passando por transformações conjunturais intensas e cada vez mais velozes. Estas transformações estão afetando a todos, sem exceção. A aproximação do terceiro milênio está predispondo e ensejando o surgimento de novos paradigmas.

Um dos paradigmas emergentes refere-se às questões ambientais. Durante décadas acreditou-se que o crescimento econômico proporcionaria melhores condições de vida para a sociedade; no entanto o que a sociedade passou a perceber é que esse crescimento econômico desenfreado estava causando danos preocupantes aos ecossistemas. O surgimento deste novo paradigma deve-se à "reviravolta nos modos de pensar e agir, [proporcionada pelo] crescimento da consciência ecológica, na sociedade, no governo e nas próprias empresas, que passaram a incorporar essa orientação em suas estratégias" (Donaire, 1995, p. 11).

Com base nesses fenômenos, percebe-se, por parte das empresas, crescente preocupação com o meio ambiente, com a saúde e segurança de seus trabalhadores, bem como sua responsabilidade social e ética perante a comunidade em que se inserem. Essas características podem ser observadas no texto da Declaração do Business Council for Sustainable Development (BCSD), assinada em 1992, na Suíça, por cerca de 50 empresários de todo o mundo.

Esta nova orientação está sendo adotada pouco a pouco pelas empresas; no entanto ela deve-se, em grande parte, a fatores externos, tais como: pressão por parte da sociedade; dos Governos; das instituições financeiras internacionais; pressão decorrente da acirrada concorrência, devido à globalização da economia; pressões de organizações não-governamentais (ONGs); conceitos novos referentes a sistemas de qualidade total - ISO 9000; gestão ambiental; certificação ambiental (BS-7750 e Norma ISO 14000) e produtos que sejam detentores de selos verdes (produtos que desde suas origens possuam elevado padrão de comprometimento com a variável ambiental), dentre outros.

Percebe-se que a sociedade está, cada vez mais, tomando consciência de que a variável ambiental é importante e que ela diz respeito a todos. É importante salientar que "o homem é Natureza, é a parte da Natureza que tem consciência de si mesma" (Cornely, 1992, p. 663, grifo não existente no original). Será essa consciência do homem que pode vir a salvá-lo da destruição, pois se trata de sua sobrevivência, bem como do próprio planeta. 
É em nome dessa consciência da sobrevivência que determinadas características de conformidade ambiental, tanto para processos como para produtos, começam a ser exigidas principalmente pela Europa e Estados Unidos. Para produtos provenientes do agribusiness brasileiro, tal procedimento pode significar a criação de barreiras protecionistas não-tarifárias, por parte dos importadores, ou seja, estrategicamente isto pode ser visto como uma ameaça.

Jum MacNeill, ex-secretário geral da Comissão Brundtland, afirmou que "os anos 90 assistiriam a uma grande escalada de leis unilateralmente sancionadas com o objetivo de impor várias restrições aos produtos em desacordo com os requisitos ambientais - conceito sob o qual se incluem o bem-estar e a saúde de seres humanos, animais ou plantas" (MacNeill apud Rodrigues, 1992, p. 3).

O que para alguns significa ameaça ou restrição em potencial, para outros pode significar novas oportunidades. Assim, tendo em vista o problema de poluição ambiental causado por empresas do agribusiness e a questão econômica que envolve a adoção de novas formas de produção (e.g.: as tecnologias mais limpas), pretende-se enfocar o trabalho para uma empresa rural de Alegrete, RS, produtora de arroz irrigado, a Fazenda Cerro do Tigre (FCT).

O objetivo geral do trabalho consiste em identificar a geração de inovações e competitividade, após a adoção da Produção Mais Limpa ${ }^{(1)}$ (PML). Como objetivos específicos, pretende-se identificar a resposta aos seguintes questionamentos: a) Quais são as expectativas destes agentes econômicos (gestores da FCT)? b) Que capacidades eles podem ter, desenvolver e explorar, buscando incrementar a vantagem competitiva de sua empresa, via adoção da PML? c) Que oportunidades podem ser vislumbradas, tendo em vista as questões ambientais?

Para tanto, toma-se como ponto de partida a premissa de que existem expectativas, capacidade empreendedora e detecção de oportunidades, por parte dos agentes econômicos da FCT. O entendimento desses fatores possibilita entender a decisão estratégica dos gestores, visando a atender às novas demandas da sociedade, em termos de produtos limpos.

Este artigo possui as seguintes seções: Expectativas dos Agentes Econômicos; Capacidade Empreendedora; Oportunidades; O Caso da Fazenda Cerro do Tigre (FCT); Considerações Finais e Anexo 1. 


\section{Expectativas dos Agentes Económicos}

Definindo-se o termo expectativa, tem-se que se trata de "esperança fundada em supostos direitos, probabilidades ou promessas" (Ferreira, 1994). Relativamente ao termo agentes econômicos, no presente trabalho, estabelece-se como sendo os gestores da FCT.

Pauli (1996) afirma que a força que prospera são as expectativas. "Se nós não pensarmos que outras perspectivas são possíveis, elas nunca se materializarão. Se pensarmos que são factíveis, estaremos prontos para imaginá-las, em cores, em estéreo ou em três dimensões" (Pauli, 1996, p. 15).

Os negócios são conduzidos por expectativas. Todavia isto não ocorre sobre a base de provas científicas. "O que os agentes econômicos esperam que ocorra e o que o mercado espera das empresas? Este é um diálogo dinâmico onde se fazem as mesmas perguntas, porém as respostas estão sempre mudando" (Pauli, 1996, p. 49). Desta forma, tem-se que o mercado é manejado por expectativas, "uma miríade complexa de reações baseada na informação objetiva e em interpretações subjetivas" (Pauli, 1996, p. 48).

As informações e as interpretações visam a amenizar a angústia da incerteza que envolve todo e qualquer processo de tomada de decisão. Assim, o produto das decisões é função da quantidade de conhecimento e informações disponíveis (Thompson, 1995). Conforme Knight (1972, p. 245), “essa capacidade de fazer julgamentos corretos (num campo mais ou menos extenso ou restrito) é o fato principal que torna o homem prestimoso nos negócios [...]".

Tendo em vista que as empresas sofrem a ação de seu meio ambiente, mas também podem influenciar este meio ambiente a seu favor, numa abordagem mais holística da questão estratégica, supõe-se que os agentes econômicos, que estão buscando formas alternativas de PML, têm como expectativa o sucesso de sua tomada de decisão, visando justamente a que sua empresa influencie na conformação deste novo meio ambiente (vide Figura 1).

Tal sucesso será medido pela aceitação de seu produto no mercado. Pode-se buscar essa aceitação pela redução do preço ou pelo aumento da qualidade do produto ofertado, visando à sua diferenciação. Essa é a ótica porteriana de busca de competitividade, como será visto mais adiante.

A expectativa dos agentes econômicos, ditada principalmente pelo desejo de buscar o lucro e pelo desejo de vencer as incertezas inerentes ao negócio, tem na busca da competitividade a justificativa de sua existência; contudo, apenas pos- 
suir expectativas não leva a caminho nenhum. Faz-se necessário que os agentes econômicos detenham algumas capacidades para transformar as expectativas em realidade. Uma destas capacidades está relacionada com o espírito empreendedor e com a vontade de inovar. Isto é o que se aborda a seguir.

\section{Figura 1: Resumo dos Principais Elementos Abordados na Teoria}

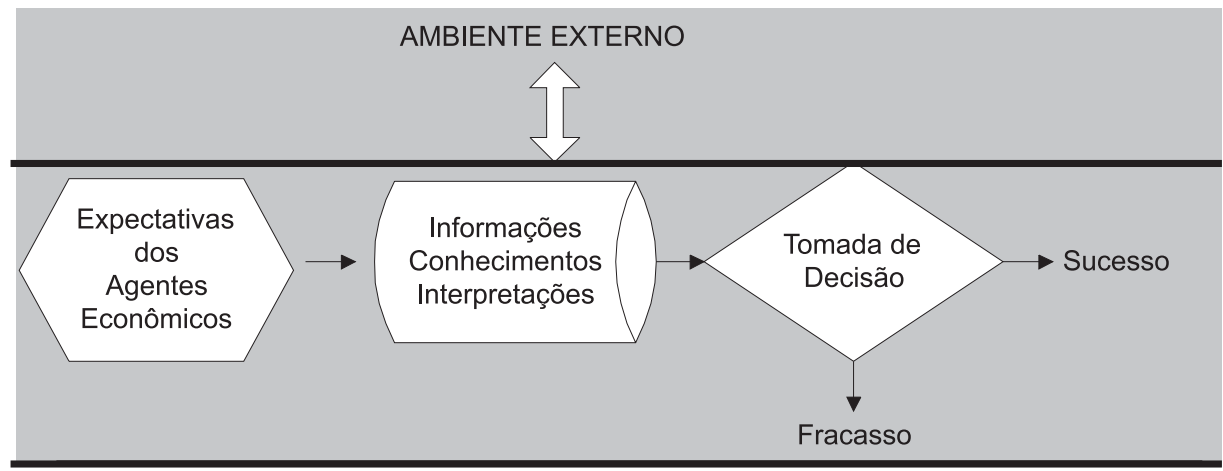

\section{CAPACIDADE EMPREendedora}

Capacidade, segundo Ferreira (1994), significa, dentre outras coisas: a) qualidade que uma pessoa ou coisa tem de possuir para determinado fim; habilidade, aptidão; b) pessoa de grande ilustração ou aptidão; talento, sumidade. Ter a capacidade de: significa ir ao ponto de; ousar.

Pode-se dizer que os agentes econômicos em tela (os gestores da FCT) podem ter, desenvolver ou explorar capacidades relativas a um espírito empreendedor que lhes possibilite vislumbrar oportunidades e realizar inovações que outros ainda não perceberam. A seguir, aborda-se a questão do empreendedor, sob a ótica schumpeteriana.

\section{O Entrepreneur}

Joseph Alois Schumpeter (1883-1950), economista austríaco, realizou grande contribuição no sentido de explicar como ocorre o processo de desenvolvimento econômico. Em seu livro The Theory of Economic Development, Schumpeter (1982) teoriza sobre o fluxo circular, que representa um sistema de reprodução econômica em equilíbrio estático. Schumpeter (1982) chegou à conclusão de que eram as inovações tecnológicas ou progresso técnico o principal gerador de mu- 
dança na economia. As inovações tecnológicas eram a origem verdadeira do lucro, pois geravam o desequilíbrio no fluxo circular. Contudo as inovações só ocorrem porque existe um agente, denominado entrepreneur.

Conforme Schumpeter (1982) o entrepreneur é aquele que realiza novas combinações, é o agente das inovações e deve ter capacidade de ação empreendedora, de previsão, de iniciativa e liderança. A função do líder consiste em assumir as coisas; esta figura só se apresenta quando surgem novas possibilidades ou potencialidades. Desta forma, a potencialidade de determinada realização é, em geral, identificada apenas pelos entrepreneurs ou empreendedores, que assumem as responsabilidades de levar adiante o empreendimento. A Figura 2 resume as relações apontadas por Schumpeter (Zawislak, 1996).

\section{Figura 2: O Fluxo Circular e a Inovação}

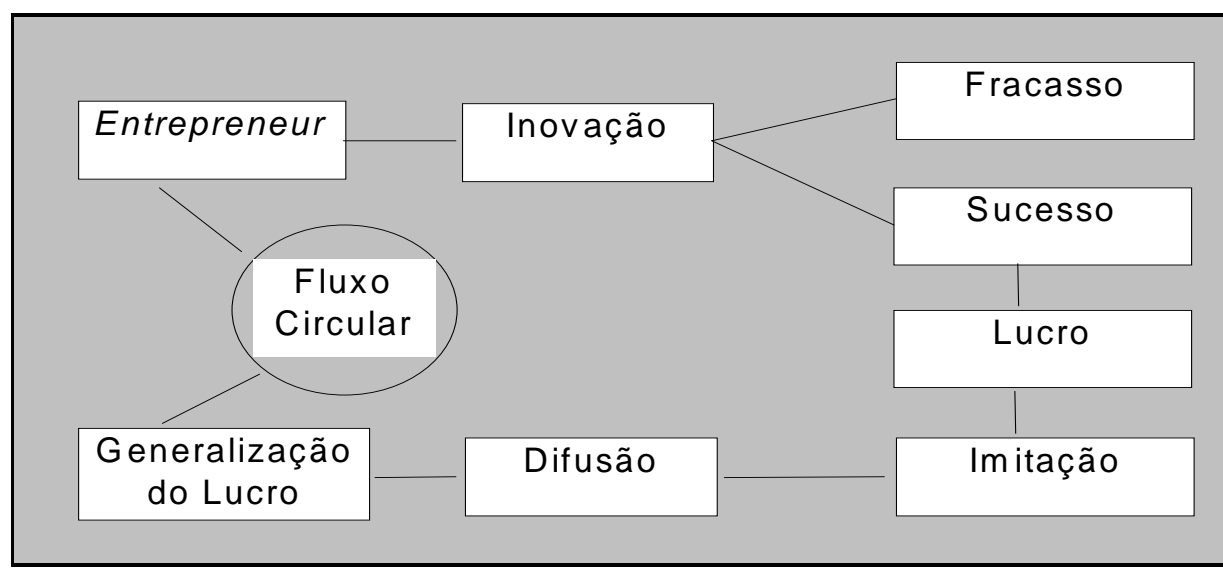

Fonte: Zawislak (1996).

Cada passo fora da rotina diária encontra dificuldades e envolve um elemento novo. A natureza das dificuldades/barreiras daqueles que saem da rotina (os inovadores e/ou empreendedores) pode ter três pontos distintos, identificados por Schumpeter (1982), conforme pode ser visto no Quadro 1, a seguir. 


\section{Quadro 1: Natureza das Dificuldades/Barreiras Encontradas pelos Inovadores}

\begin{tabular}{|l|l|}
\hline $\begin{array}{l}\text { Natureza das } \\
\text { dificuldades }\end{array}$ & Descrição \\
\hline 1) Tarefa & $\begin{array}{l}\text { A dificuldade de realizar algo novo é que não existem referências sobre o novo, ou seja, ele } \\
\text { é apenas fruto da imaginação. É correto que o inovador deve prever e julgar com base na sua } \\
\text { experiência; entretanto muitas coisas ainda permanecem incertas. Neste momento, o } \\
\text { inovador deve planejar conscientemente a sua conduta em todos os particulares; contudo } \\
\text { deve ter em mente a impossibilidade de examinar exaustivamente todos os possíveis } \\
\text { resultados do empreendimento. O sucesso depende da intuição, da capacidade de ver as } \\
\text { coisas de modo diferente e da captação do fato essencial. }\end{array}$ \\
\hline \hline $\begin{array}{l}\text { 2) Psique do } \\
\text { empreendedor }\end{array}$ & $\begin{array}{l}\text { É muito mais difícil fazer algo novo do que fazer o que já é conhecido e testado pela } \\
\text { experiência. Os hábitos arraigados de pensar produzem resultados automáticos, tornando-se } \\
\text { os grilhões das novas idéias. É necessária uma força de vontade nova, para encontrar dentro } \\
\text { da rotina diária, oportunidade e tempo para conceber e elaborar uma nova combinação e nela } \\
\text { identificar uma possibilidade real e não meramente um sonho. Essa liberdade mental } \\
\text { pressupõe um grande excedente de força sobre a demanda cotidiana e é algo peculiar e raro } \\
\text { por natureza. }\end{array}$ \\
\hline \hline $\begin{array}{l}\text { 3) Reação do } \\
\text { meio ambiente } \\
\text { social }\end{array}$ & $\begin{array}{l}\text { A reação pode revelar-se pelos impedimentos legais ou políticos ou, então, por condenação } \\
\text { do grupo social a que pertence o empreendedor. Superar essa oposição requer um gênero } \\
\text { especial de trabalho e de conduta. Essa resistência, em questões econômicas, se manifesta, } \\
\text { principalmente: } \\
\text { a) nos grupos ameaçados pela inovação; } \\
\text { b) na dificuldade para encontrar a cooperação necessária; } \\
\text { c) e na dificuldade para conquistar os consumidores. }\end{array}$ \\
\hline
\end{tabular}

Fonte: adaptado de Schumpeter (1982, p. 60-61).

Machiavel, na obra O Príncipe, em 1513, já havia identificado a dificuldade que o inovador sofre, no que se refere à reação do meio ambiente social. Conforme este autor, "nada é mais difícil de assumir, nem mais perigoso para conduzir, do que tomar a iniciativa na introdução de uma nova ordem, pois o inovador tem como inimigos aqueles que tiraram proveito das velhas condições e como defensores tímidos aqueles que podem tirar proveito da nova ordem" (Machiavel, 1990, grifo não existente no original).

Como foi visto acima, existem certas dificuldades que o inovador precisa vencer antes de tornar-se bem-sucedido. Sabendo-se essas dificuldades, cabe perguntar: que é que motiva um entrepreneur? Schumpeter (apud Heilbroner, 1996), aponta três motivos que levam o inovador/empreendedor a assumir riscos e atitudes que podem gerar a condenação do grupo social a que pertence: a) o sonho e a determinação de fundar um reino particular ou uma dinastia; b) a vontade de conquistar, o impulso de lutar, de provar que é superior aos outros; c) a alegria de criar, de fazer coisas ou apenas de utilizar a própria energia e imaginação. Os que possuem motivações semelhantes e conseguem colocar em prática sua inovação ou idéia estão utilizando sua capacidade de entrepreneurship ou empreendimento.

Entrepreneurship, conforme Stevenson e Jarillo (1990), é um processo pelo qual os indivíduos - sozinhos ou atuando em organizações - perseguem as oportu- 
nidades sem considerar os recursos presentes. O processo de entrepreneurship é analisado pelos autores levando em consideração três elementos (vide Figura 3):

\section{Figura 3: Os Elementos do Processo de Entrepreneurship}

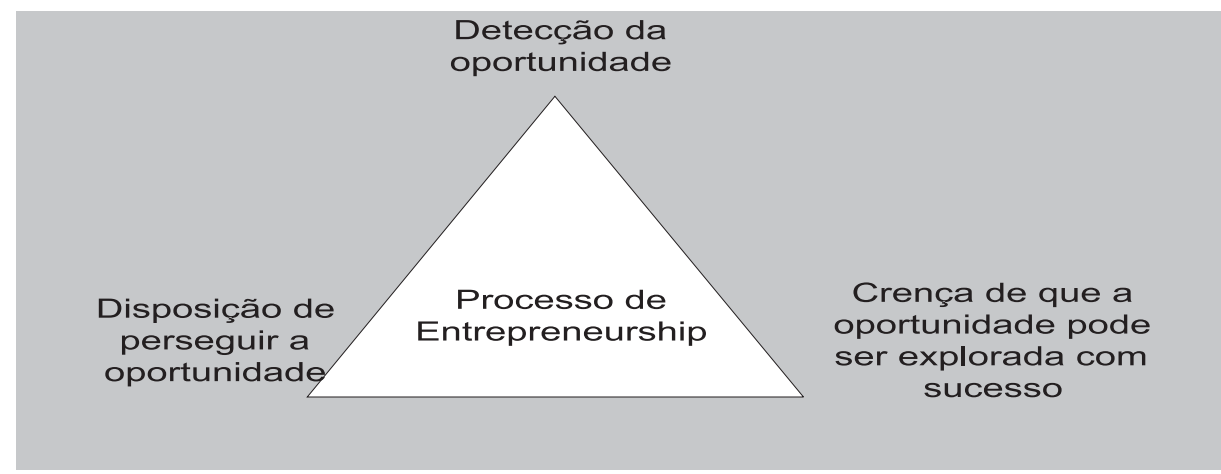

Fonte: adaptado de Stevenson e Jarillo (1990).

Saber explorar esses elementos é utilizar-se da capacidade empreendedora, tanto para indivíduos como para organizações. No caso das empresas, faz-se também necessário combinar uma noção de destino, uma profunda compreensão das tendências tecnológicas e um sonho vívido de como melhorar a vida das pessoas (Hamel e Prahalad, 1994). Essas qualidades ajudam a mover as engrenagens do progresso técnico e da inovação tecnológica.

Abordaram-se até aqui questões sobre as expectativas dos agentes econômicos e as capacidades que eles podem ter, desenvolver ou explorar, visando a identificar oportunidades que propiciem inovações rentáveis para suas empresas. $\mathrm{Na}$ sequiência, trata-se de questões relativas à detecção dessas oportunidades e a tomada de decisões estratégicas que visem a explorá-las com sucesso.

\section{Oportunidades}

Oportunidade, conforme Ferreira (1994) significa, a) qualidade de oportuno; b) ocasião, ensejo, lance; c) circunstância adequada ou favorável; conveniência. Oportuno é o que vem a tempo, a propósito, ou quando convém; apropriado; o que é cômodo, favorável.

Conforme Kotler (1991), uma oportunidade é uma área de atração que pode trazer vantagem competitiva para a empresa. Uma ameaça é um desafio imposto por tendências desfavoráveis do ambiente. 
A janela de oportunidades, aberta pelas questões ambientais, pode ser delineada a partir de vários aspectos. Pretende-se abordar estas questões colocando-se em segundo plano os posicionamentos românticos, passionais e bucólicos referentes ao meio ambiente. $\mathrm{O}$ tom deste trabalho será dado pelas questões mais pragmáticas.

Desta forma, adota-se aqui a postura da teoria evolucionária da mudança econômica de Nelson e Winter (1982), que diz o seguinte: os atores econômicos, principalmente as empresas, possuem objetivos que eles perseguem. O lucro é um destes importantes objetivos; portanto, torna-se complicado para as empresas, quando há um descasamento entre a melhoria de sua condição ambiental e sua lucratividade.

Neste princípio de obtenção de lucro, pode-se dizer que a teoria evolucionária iguala-se à teoria neoclássica. No entanto, para os evolucionistas, a questão é muito mais de buscar o lucro ou realizar esforços motivados pelo lucro do que simplesmente a maximização do lucro da teoria neoclássica. Assim, explica-se a adoção da postura evolucionista, pelas seguintes razões:

. as empresas, onde os agentes econômicos atuam, estão identificadas com a figura do empreendedor, que é aquele que assume riscos, toma decisões e recebe as recompensas;

- o agribusiness (a empresa pesquisada pertence a este setor) possui características de mercados competitivos, em que a busca dos lucros é condição de sobrevivência;

. as estratégias implementadas podem diferir de empresa para empresa, em parte por causa das diferentes interpretações das oportunidades e limitações econômicas e em parte porque as empresas possuem capacidades diferentes entre si. Desta forma, cada empresa vai adotar as mais variadas estratégias para que o seu objetivo máximo seja alcançado.

As razões acima citadas configuram os esforços de busca do lucro ou esforços motivados pelo lucro e não somente maximização do lucro, tendo em vista a detecção de oportunidades e a adoção de determinadas estratégias para o aproveitamento delas. Teóricos da área de estratégia costumam sinalizar três condições essenciais, para que uma empresa tenha sucesso e consiga maximizar seus lucros (vide Quadro 2). 


\section{Quadro 2: Condições e Estratégias para a Empresa Maximizar o Lucro}

\begin{tabular}{|l|l|}
\hline Condições & Estratégia \\
\hline $\begin{array}{l}\text { 1) A empresa precisa estabelecer e implementar um } \\
\text { conjunto de objetivos e metas funcionais e políticas } \\
\text { que a ajudem a definir sua posição no mercado. }\end{array}$ & $\begin{array}{l}\text { A estratégia é vista como uma forma de integrar as } \\
\text { diversas atividades da empresa. }\end{array}$ \\
\hline \hline $\begin{array}{l}\text { 2) Este conjunto de objetivos e metas estabelecidos } \\
\text { facilitam a definição das forças e fraquezas da } \\
\text { empresa com relação às oportunidades e ameaças do } \\
\text { mundo externo. }\end{array}$ & $\begin{array}{l}\text { A estratégia é vista como uma forma de alinhar a } \\
\text { empresa com o seu ambiente. }\end{array}$ \\
\hline \hline $\begin{array}{l}\text { 3) Criação e exploração das capacitações-chaves } \\
\text { (core competences) da empresa. }\end{array}$ & $\begin{array}{l}\text { A estratégia é vista como uma forma de aglutinar e } \\
\text { explorar o que na realidade são as únicas forças } \\
\text { que uma empresa possui, ou seja, os seus recursos. }\end{array}$ \\
\hline
\end{tabular}

Fonte: adaptado de Porter (1991).

Adotando-se a ótica porteriana, cabe salientar que todas as decisões estratégicas da empresa devem ser tomadas mediante a consideração da variável ambiente externo. Para que as empresas tenham sucesso competitivo é preciso que a estratégia adotada conecte as circunstâncias ambientais ao comportamento da empresa, com relação aos resultados de mercado.

Porter (1985) propôs que as empresas, para se tornarem competitivas, precisam adotar uma das três estratégias genéricas amplas definidas por ele: custo, diferenciação ou enfoque (em custo ou em diferenciação). A vantagem competitiva surge pelo valor que uma empresa consegue criar para seus clientes, sendo que este valor deve ultrapassar o custo de fabricação pela empresa. A meta final da vantagem competitiva é modificar as regras do ambiente externo em favor da empresa, ou seja, criar assimetrias de mercado que melhorem sua competitividade.

A competitividade pode ser definida como a capacidade de a empresa formular e implementar estratégias concorrenciais, que lhe permitam ampliar ou conservar, de forma duradoura, uma posição sustentável no mercado. Ela é função da adequação das estratégias das empresas individuais ao padrão de concorrência vigente no mercado específico (Ferraz, Kupfer e Haguenauer, 1995).

Analisando-se as questões ambientais como estão colocadas hoje, pode-se dizer que elas são potencialmente criadoras de ameaças para as empresas em geral. Como transformar estas ameaças em oportunidades ou em vantagem competitiva?

Ferraz, Kupfer e Haguenauer (1995, p. 338) vislumbram que, "dada a capacitação produtiva e tecnológica existente no país, a questão ambiental oferece a oportunidade de constituir-se em uma das bases de renovação da competitividade das empresas brasileiras"; contudo faz-se necessária a adoção de uma postura pró-ativa com relação ao meio ambiente, por parte dos empresários. 
Esta atitude pró-ativa pode construir, a médio e longo prazo, vantagens competitivas de difícil superação pelos competidores, conforme Ferraz, Kupfer e Haguenauer (1995).

Desta forma, janelas de oportunidades começam a se abrir para aqueles que já estão pensando e agindo proativamente sobre a questão ambiental. A seguir, identificam-se alguns sinais que ajudam a compor o quadro de probabilidades e tendências para a futuro, no que concerne às questões ambientais. Entretanto não se pretende ser exaustivos nesta enumeração.

- Os ecoprodutos, produtos verdes ou environmental friendly (amigos do meio ambiente) começam a surgir com força e sinalizam que está nascendo um novo paradigma de consumo. Atualmente, o ecobusiness está movimentando cerca de US\$ 230 bilhões e absorvendo 1\% do total da mão-de-obra nos países mais desenvolvidos (SEBRAE et al., 1996).

- As exportações do ecobusiness são responsáveis por cerca de 5 a $10 \%$ da produção dos países desenvolvidos (SEBRAE et al., 1996).

- O vetor de crescimento do mercado de ecobusiness é a elevação do grau de consciência ambiental da população (SEBRAE et al., 1996).

- O ecobusiness é um mercado em expansão, sendo que até o ano 2000 está previsto que ele dobrará de tamanho, chegando a US $\$ 580$ bilhões (SEBRAE et al., 1996).

- Uma pesquisa de mercado, elaborada pelo Instituto Gallup e realizada com 22 países (ricos e pobres), indicou que 53\% dos entrevistados disseram estar dispostos a pagar um preço mais alto pela proteção do meio ambiente. Também responderam assim $71 \%$ dos brasileiros pesquisados (Maimon, 1994).

- Conforme Coddington (apud Brito e Carin, 1996), estar inserta em uma escala de produção ambiental não agressiva pode significar para a empresa a possibilidade de agregar valor aos seus produtos, ou seja, ela poderá ter um preço prêmio para eles, pois existe sinergia entre gestão ambiental e marketing ecológico.

- Em termos estratégicos e mercadológicos, os produtos verdes podem ser utilizados com a característica de diferenciação. Não obstante, esses produtos também podem reduzir os custos de produção da empresa. Tem-se aí dupla vantagem (SEBRAE et al., 1996).

- O Market-Based Environmentalism (MBE) ou mercado baseado no ambientalismo é um paradigma emergente. Ele desafia a visão ortodoxa de 
que objetivos ecológicos e objetivos de mercado são incompatíveis. Relacionamentos cooperativos tais como as alianças verdes e as regulamentações economicamente amigáveis (economically-friendly) são fenômenos novos que, todavia, podem ser implementados estrategicamente pelas empresas (Hartmann e Stafford, 1997).

- Em termos econômicos, mercadológicos e ambientais, é muito menos dispendioso prevenir a poluição do que recuperar áreas ambientalmente degradadas e imagens empresariais corrompidas por acidentes ecológicos. $\mathrm{Ci}$ tam-se, neste sentido, os casos da Bhopal e Exxon, afetando a Union Carbide e Exxon Valdez, respectivamente (Hunt e Auster, 1990).

- A questão ambiental pode ser vista como forma de reduzir custos. Visto que a maioria dos processos produtivos atualmente utilizados são muito intensivos em utilização de energia e de matéria-prima, a empresa que conseguir modificar seus processos e/ou produtos diminuindo estes insumos pode obter ganhos reais (SEBRAE et al., 1996).

- A questão ambiental, além de gerar novas oportunidades de negócios, pode propiciar o surgimento de inovações tecnológicas importantes. "Inovar para adequar-se às regulamentações pode trazer compensações: utilizar melhor os inputs; criar produtos melhores ou melhorar os resultados do produto" (Porter e Linde, 1995).

Todas essas questões apontam para janelas de oportunidades e podem ser analisadas à luz do pensamento de Hamel e Prahalad (1995). Estes autores sugerem que os empresários precisam desenvolver, urgentemente, uma visão de futuro. Além de desenvolver esta visão, é preciso que o futuro seja criado pela empresa: a empresa precisa criar hoje as assimetrias de mercado que a favorecerão no futuro.

Conforme Hamel e Prahalad (1994, p. 64), "o truque consiste em ver o futuro antes que ele chegue" e identificar as oportunidades de atuação. Para esses autores, uma empresa que não seja capaz de assumir "um compromisso emocional e intelectual com a criação do futuro, mesmo na falta de uma razão comercial financeiramente irrefutável, certamente será apenas uma seguidora" (Hamel e Prahalad, 1994, p. 42). Saber identificar oportunidades não percebidas por outras empresas e explorar essas oportunidades, mediante a reunião e geração das core competences ou capacitações-chaves necessárias, pode ser o diferencial entre sobreviver ou morrer (Hamel e Prahalad, 1994).

A seguir, trata-se do estudo de caso, em que se apresentam as características encontradas na FCT, levando-se em consideração a teoria contemplada. 


\section{O Caso da Fazenda Cerro do Tigre}

\section{Descrição da Empresa}

A Fazenda Cerro do Tigre (FCT) possui 2.270,9 ha e está inserta em uma região de várzeas e coxilhas, no Tigre, segundo distrito do município de Alegrete, no Estado do Rio Grande do Sul. Cerca de 720 ha, dos 2.270,9 ha de propriedade da fazenda, foram destinados ao cultivo de arroz irrigado, ano-base 1997/98, área produtiva alvo da pesquisa.

A FCT é uma propriedade que vem passando de geração para geração da família Dorneles, de Alegrete, estando envolvida com a orizicultura por mais de 80 anos. O sr. Eurico é o proprietário da Fazenda Cerro do Tigre, estando no seu comando há cerca de 40 anos. Após os filhos Dóris e Júnior manifestarem o desejo de atuarem profissionalmente na empresa, Eurico passou-lhes a responsabilidade de administrá-la.

A empresa conta com mais quatro gestores, a saber: a) Ivo, engenheiro agrônomo, responsável pela área orizícola (produção, beneficiamento, armazenagem); b) Júnior, zootecnista, responsável pela produção, comercialização e manejo da pecuária de corte e ovina e pelas culturas alternativas na coxilha, tais como, milho, soja, sorgo, pastagens, além da produção de morangos ecológicos (sem nenhum insumo químico); c) Dóris, engenheira agrônoma, responsável pela parte administrativa da empresa; d) Ana, engenheira agrônoma, responsável pela compilação dos dados para o gerenciamento dos custos.

Além dos quatro gestores (Ivo, Júnior, Dóris e Ana), a empresa possui mais 32 funcionários, assim distribuídos: escritório (2); lavoura (26); residências da fazenda (4).

Os principais produtos da empresa são o arroz agulhinha, que é comercializado com casca, e o arroz cateto integral ecológico, que é comercializado já beneficiado e embalado. Esses processos (beneficiamento e embalagem) são feitos dentro da própria FCT. A comercialização do produto diferenciado (arroz integral ecológico) atualmente é feita pela Coolméia (Cooperativa Ecológica de Porto Alegre).

Os principais clientes para o arroz agulhinha com casca são a Éffem Produtos Alimentícios e a empresa de Onélio Pileco. O arroz cateto integral ecológico, que responde por quase $3 \%$ da produção da empresa, é vendido principalmente para a Coolméia. Este produto já sai embalado com a marca da Coolméia e com selo indicativo de que é produzido na FCT. 
Os principais fornecedores da empresa são Calcário Vigor; Adubo e Fertilizantes Piratini; Cooplantio; Semeato, Jacto, SLC Colheitadeiras e Pneus Witt.

No ano-base 1996/97, a FCT investiu R $\$ 27.000,00$, cerca de 2,8\% de seu faturamento bruto, em treinamento de recursos humanos; $\mathrm{R} \$ 4.330,00$ em compra de novas máquinas, desenvolvimento de experiências; $\mathrm{R}$ \$22.670,00 em testagens de novas tecnologias.

A FCT, tendo em vista seu caráter pioneiro, suas atitudes perante a comunidade e seus produtos, já foi agraciada com diversos prêmios e troféus, bem como seus gestores, sendo os mais expressivos o Prêmio Ecologia, recebido na Expointer de 1996 e o Prêmio Destaque Rural, concedido pela FARSUL e pelo SENAR, categoria Propriedade, em 1996.

\section{As Expectativas dos Agentes Econômicos}

As expectativas dos gestores, em termos da adoção da PML, têm que ver com questões relativas à responsabilidade social e à conformidade ambiental, mas também e principalmente com a vantagem competitiva e com a possibilidade de que novos negócios sejam integrados à empresa. Tais expectativas podem ser resumidas em duas palavras: expectativas econômicas.

Relativamente à responsabilidade social e à conformidade ambiental, que englobam a consciência ambiental, o ecocentrismo, a ética empresarial e os stakeholders verdes, identificou-se, por meio de manifestações dos gestores (G) e dos terceiros $(\mathrm{T})^{(2)}$ (vide Anexo 1): a existência de certas atitudes que denotam essas características como, por exemplo, a preocupação ambiental para com os consumidores e com as gerações futuras; a satisfação interior de não estar enganando os consumidores; o entendimento de que cada cidadão é responsável e deve influir em sua zona de atuação; o comprometimento para com as modificações técnicas necessárias; investimento para realização das modificações; a difusão de tecnologias e conhecimentos adquiridos entre os participantes de sua cadeia produtiva; modificação da cultura dos colaboradores etc.

A expectativa com relação à vantagem competitiva, envolvendo questões de diferenciação e redução de custos, foi identificada por manifestações com as seguintes características: percepção de que é possível potenciar o produto arroz pela diferenciação e pela agregação a ele de novo valor; criação de marca e de imagem positiva da empresa; utilização de tecnologias diferenciadas de plantio, visando a reduzir custos e a melhorar as condições do meio ambiente, como a adoção do plantio direto, por exemplo (vide Anexo 1). 


\section{A Capacidade Empreendedora}

Tendo em vista que a capacidade inovadora e pioneira depende de determinadas características empreendedoras dos gestores, identificaram-se, na entrevista deles e com terceiros, determinados sinais indicadores desta capacidade. Eis alguns indicativos: o fato de estarem sempre pensando no negócio e sempre buscando novas alternativas; a busca constante de informação; buscar olhar os problemas sob diferentes ângulos, visando chegar a soluções mais acertadas; aposta nas idéias que surgem; satisfação com o trabalho realizado e necessidade de realização; exercício do pensamento e da criatividade; aceitação de riscos tidos como moderados; confiança de que terão sucesso; tendência de pensar o futuro; habilidade criativa na solução de problemas etc (vide Anexo 1).

\section{As Novas Oportunidades}

Relativamente às novas oportunidades de negócio - englobando as iniciativas estratégicas, inovação de produto, um portfólio mais verde, novas aplicações e um produto mais limpo - que os gestores estão vislumbrando, tendo em vista principalmente as questões ambientais e a PML, identificaram-se as seguintes idéias, nas entrevistas em profundidade com eles: criar um fast-food do arroz em Porto Alegre; industrializar a matéria-prima, gerando produtos diferentes (biscoitos de arroz e bolachinhas); ter a marca própria nos produtos; continuar fornecendo para empresas exigentes, como a Éffem e a Coolméia; fundar uma cooperativa; desenvolver o agroecoturismo, devido às peculiaridades da fazenda; produção de sementes certificadas de arroz (vide Anexo 1).

\section{As Inovações}

Com a adoção das atitudes pró-ativas e empreendedoras, por parte dos gestores da FCT, ocorreram diversas inovações tecnológicas (de processo, de produto e gerenciais). Eis algumas destas inovações.

. Processo: adoção do sistema de plantio direto; plantio direto com cultivo mínimo; utilização das taipas de base larga na orizicultura; criação da taipadeira de base larga, em conjunto com outros produtores; sistematização dos solos; rizipiscicultura; pré-germinado; transplante de mudas.

. Produto: de arroz agulhinha com muitos agroquímicos para o arroz cateto integral ecológico; de arroz agulhinha com muitos agroquímicos para um arroz agulhinha com menos produtos químicos e/ou com produtos químicos mais suaves (menos agressivos ao meio ambiente e às pessoas); de um arroz 
com altas taxas de arroz vermelho (10\%), que estava inviabilizando a produção, para um arroz de qualidade Tipo 1; os morangos ecológicos; o PesquePague; o agroecoturismo; o negócio de sementes de arroz.

. Gerencial: valorização dos recursos humanos; propiciar conhecimentos aos funcionários; os funcionários sentem-se parte integrante do processo e da gestão da empresa; existe liberdade de expressão; existe baixa rotatividade dos funcionários; os funcionários, assim como os próprios gestores, possuem motivação facilmente identificável; após a introdução dos novos sistemas de cultivo, surgiu uma nova maneira de lidar com a lavoura, ocorrendo a necessidade de ter de planejar com antecedência todos os passos de sua implantação.

\section{A Competitividade}

A competitividade pôde ser identificada por meio de informações, sintetizadas no quadro a seguir. Este quadro visa propiciar melhor identificação de vantagens competitivas trazidas pela PML, em termos econômicos, por meio da comparação da produção do arroz commodity com a do arroz ecológico, com base na safra 1996/97, da FCT.

\section{Quadro 3: Comparativo entre a Produção do Arroz Commodity e do Ecológico, Ano-Base 1996/97, FCT}

\begin{tabular}{|c|c|c|c|c|c|c|c|}
\hline Produto & $\begin{array}{c}\text { \% Área } \\
\mathbf{6 0 0 h a}\end{array}$ & $\begin{array}{c}\text { Custo de } \\
\text { produção* } \\
\text { R\$/ha }\end{array}$ & $\begin{array}{c}\text { Produtividade } \\
\text { média } \\
\mathbf{k g} / \mathbf{h a}\end{array}$ & $\begin{array}{c}\text { Remuneração } \\
\mathbf{R} \$ \mathbf{5 0 k g}\end{array}$ & $\begin{array}{c}\text { Receita } \\
\mathbf{R} \$ \mathbf{h a}\end{array}$ & \multicolumn{2}{|c|}{$\begin{array}{c}\text { Margem } \\
\text { operacional } \\
\text { R\$/ha e } \%\end{array}$} \\
\hline $\begin{array}{c}\text { Arroz } \\
\text { commodity }\end{array}$ & $\begin{array}{c}95,70 \% \\
574,2 \mathrm{ha}\end{array}$ & 975,00 & 5000 & 12,00 & $1.200,00$ & 225,00 & $18,75 \%$ \\
\hline $\begin{array}{c}\text { Arroz } \\
\text { ecológico }\end{array}$ & $\begin{array}{c}4,30 \% \\
25,8 \mathrm{ha}\end{array}$ & 825,00 & 4500 & 15,00 & $1.350,00$ & 525,00 & $38,89 \%$ \\
\hline
\end{tabular}

Fonte: pesquisa de campo

*Obs.: Os valores de custeio incluem no seu cálculo a depreciação, o custo de oportunidade da terra etc.

Conforme se depreende deste quadro, o custo de produção do arroz ecológico é menor em R \$ 150,00 ou 15,4\%. Entretanto a produtividade do arroz ecológico ainda não alcançou o mesmo valor do arroz commodity; convém salientar que a produção do arroz ecológico ainda se encontra na fase inicial de sua curva de aprendizado, o que pode acarretar a diminuição da produtividade. Cumpre salientar ainda que a produtividade do arroz commodity é maior, pois é feita a incorporação de fertilizantes químicos (uréia) à lavoura.

Mesmo com produtividade menor de $10 \%$, o arroz ecológico possui margem operacional de $38,89 \%$ contra a margem operacional de $18,75 \%$ do arroz commodity, ou seja, uma diferença de $20,14 \%$. 
Comprovando-se ainda mais a competitividade do arroz ecológico perante o arroz commodity, resgatam-se os valores de mercado obtidos pelo produto, anotados em dezembro de 1997. Com relação ao preço para o consumidor final do arroz tipo commodity, nas principais redes de supermercado de Porto Alegre, os preços por $1 \mathrm{~kg}$ do produto variaram entre $\mathrm{R} \$ 0,75$ a $\mathrm{R} \$ 0,99$, em dezembro de 1997. Relativamente ao arroz diferenciado (cateto integral) encontrou-se uma variação bem maior. Para $1 \mathrm{~kg}$ deste produto, houve preços entre $\mathrm{R} \$ 1,75$ a $\mathrm{R} \$$ 2,76, em dezembro de 1997. Nessa mesma época, o preço da Coolméia para o arroz cateto integral orgânico estava em $\mathrm{R} \$ 1,32$ e para o arroz agulhinha integral orgânico, $\mathrm{R} \$ 1,03$. Esses valores denotam que o arroz diferenciado recebe um preço maior, até mesmo na Cooperativa de Produtores (Coolméia).

\section{Considerações Finals}

Respondendo-se aos objetivos geral e específicos propostos para este artigo, tem-se que, para a pergunta a) dos objetivos específicos - Quais são as expectativas destes agentes econômicos (gestores da FCT)? - identificou-se que os gestores têm expectativas econômicas, pois acreditam que o mercado para produtos saudáveis e ambientalmente corretos está em fase de expansão acelerada. $\mathrm{O}$ anseio dos consumidores por produtos limpos pode ser observado, principalmente, nos países desenvolvidos. Com a visão de que esta é a grande tendência dos mercados do futuro, se não os de agora, a FCT está rumando para tornar-se, cada vez mais, uma propriedade rural sustentável.

Com relação à pergunta b) - Que capacidades eles podem ter, desenvolver e explorar, buscando incrementar a vantagem competitiva de sua empresa, via adoção da PML? - pode-se dizer que os gestores já possuem características empreendedoras que facilitam o incremento da vantagem competitiva da FCT, via geração de inovações, sempre tendo em vista a questão da PML.

Para a pergunta c) - Que oportunidades podem ser vislumbradas, tendo em vista as questões ambientais? - identificou-se que os gestores possuem uma capacidade distinta, em termos de visão de futuro. Assim, suas expectativas, neste sentido, são de que a PML é tendência mundial inquestionável. Quem desenvolver agora os caminhos em direção a uma PML, pode ser um dos primeiros a colher os frutos dessa nova tendência mercadológica; portanto está bastante claro para os gestores da FCT que seu objetivo atual é oferecer ao mercado um produto diferenciado, sem agrotóxicos, um produto ecológico de marca própria.

Com essa estratégia pretendem atingir nichos específicos de mercado. De fato, 
constata-se que a FCT se prepara e se capacita para atender a estes nichos. A PML pode ser considerada como alicerce do novo negócio em que a empresa pretende atuar, o agroecoturismo. Esse novo negócio baseia-se nos conceitos de uma alimentação mais pura e saudável (sem agrotóxicos) e no meio ambiente preservado, para que a fruição das pessoas, naquele lugar, seja plena.

Respondendo-se ao objetivo geral do trabalho, que era identificar a geração de inovações e competitividade, após a adoção da PML, tem-se que foram identificadas diversas inovações, tanto de processo, como de produto e de gerência. Essas inovações trouxeram maior competitividade para a FCT, como pôde ser constatado pelo estudo de caso.

\section{ANEXO 1}

Manisfestações dos gestores (G) da Fazenda Cerro do Tigre e dos terceiros (T), entrevistados por ocasião da pesquisa de campo.

\section{Responsabilidade Social e Consciência Ambiental}

1. (G) Se eu usar um agroquímico qualquer, eu vou conseguir um ganho maior, mas que custo esse ganho vai trazer para as pessoas das gerações futuras e para os consumidores?

2. (G) É para o bem-estar teu, para uma satisfação tua, por que eu acho que é difícil tu trabalhares ou fazeres alguma coisa, sabendo que aquilo ali vai acabar prejudicando alguém. Então, quanto mais natural e quanto mais tu puderes proporcionar satisfação para a pessoa acho, que é melhor. Tu não estás enganando a pessoa, o teu consumidor.

3. (G) Eu não desejo para os outros aquilo que não desejo para mim, ou seja, comer produtos envenenados com agroquímicos.

4. (G) Eu prefiro um mundo limpo, sem veneno.

5. (T) Então, lógico, como o Ivo tinha toda essa sensibilidade de ser um pioneiro, logicamente que ele se sensibilizou também por todas essas colocações. E viu que ele também tinha responsabilidade como cidadão. Até porque ele é uma pessoa proeminente nas relações onde ele tem influência. Ele achou, então, que também tinha de fazer uma proposta dessas. Então é isso o que eu sinto que ele está vivendo hoje. Então tu vês que a área dele para o produto ecológico é pequena, em relação à área do produto químico; mas é justamente assim. Nós 
também temos essa relação de que tanto a pessoa deve saber o lugar onde ela está e ela deve saber como deve caminhar, na realidade dela.

6. (T) São poucos os que têm assim a questão voltada para a parte técnica, voltados para a PML, e que estão investindo do próprio bolso, e que transferem gratuitamente esse conhecimento para quem se interessar. Eles viajam muito. O Ivo esteve em Cuba, na Venezuela; então isso aí tudo é a integração [...] é muito bonito o trabalho deles.

7. (T) Então, o pessoal têm educação e formação de opinião voltada para a pessoa. Não são egocêntricos, mas de uma evolução. Eles são de evoluir, dentro do sistema e do grupo. Essa é a educação que o Ivo está transmitindo para seus colaboradores. É uma cultura que está sendo impregnada na cabeça deles.

\section{Expectativas com a Vantagem Competitiva}

8. Então, com essa participação na Coolméia a gente começou a materializar como sendo um negócio. Pela primeira vez, a gente materializou como sendo um negócio o fato de a gente estar produzindo um produto diferenciado dos outros. Como negócio, como vantagem competitiva, ou seja lá como queira chamar, uma "descommoditização" do produto.

9. A gente está almejando ter vantagem competitiva, pois está se buscando um diferencial nos nossos produtos. Queremos agregar valor ao produto, ter uma marca, ter imagem positiva, que se consiga explorar.

10. Vocês acreditam que vocês conseguem diferenciar o produto de vocês? Acho que sim. É uma tendência mundial. E acho que em cima do arroz, porque o arroz ecológico integral já está abrindo as portas nisso aí. Automaticamente, os outros produtos vão andar atrás.

11. O arroz ecológico integral a gente já vende na Coolméia. A Coolméia é de Porto Alegre. Sim, e aqui em Alegrete também já tem um restaurante, o Piattolle, que faz o nosso arroz. Eles têm o maior orgulho de ter o arroz ecológico integral. Eles estão divulgando e as pessoas estão comendo mais.

12. No plantio direto, por exemplo, os custos são menores. E com o arroz ecológico integral, também se observa a redução de custos, pois o outro arroz - o polido, já tem mais um processo - o polimento. Então, os custos são menores com a PML.

13. Só que nós ainda não conseguimos atingir o estágio de ter produtividade 
alta com a PML; mas como a gente está reduzindo bastante os custos de produção, isso auxilia no fechamento final das contas.

\section{Capacidade Empreendedora}

14. (G) A gente costuma dormir, comer, trabalhar em cima disso. A gente está sempre pensando na empresa. Aonde tu vais, às vezes, não tem nada que ver com a produção; tu estás em lazer ou algo assim, daí a pouco tu te lembras, ou tu olhas alguma coisa em outro setor; então tu acabas adaptando. Tu estás sempre em função. Tem que dormir e comer e é $\mathbf{2 4}$ horas por dia pensando em alternativas. O que a gente vai fazer? Como a gente vai fazer? Com quem a gente vai falar?

15. (G) Por isso é que eu digo que a busca de informação é constante, independente de onde tu vais e do assunto que está sendo tratado.

16. (G) Mas é o tipo da coisa assim: A questão é de tu começares a olhar fora do "quadrado".

17. (G) Então, é o tipo da coisa [...] foi uma idéia que surgiu [...] eu estava pensando [...] mas se eu pegar e juntar dois mais dois vai dar quatro! E é nesse sentido que eu te digo. Cada ano que passa a gente faz um negócio novo, que dá satisfação! O transplante de mudas, por exemplo, é a menina dos meus olhos. A primeira coisa que eu faço, quando eu entro aqui na fazenda, é ir olhar o trabalho, porque tu vês o que já andou e o que já está cumprido.

18. (G) Eu sempre tive idéias. Sempre fui metido e sempre tive essa mania de pensar e ser meio criativo; mas no começo, como eu era novo, eu não entendia, não sabia e, na cabeça de todo o mundo, não me davam muita bola, vamos dizer assim $[\ldots]$.

19. (G) Eu acho que a gente tem que mostrar aos filhos que determinadas coisas que estão acontecendo não são à toa. Elas acontecem porque a gente está trabalhando, porque a gente se esforça, porque a gente faz.

20. (G) Pode ser risco para a maioria das pessoas. Para mim isto não é risco, pois tu acreditas tanto naquilo, tu tens assim uma sensação tão forte de que aquilo vai funcionar, que vai dar certo, que não é risco, entendeu?

21. (G) O pai [sr. Eurico], sempre foi uma pessoa que teve coceira por dentro! Ele nunca conseguiu ficar achando que estava tudo bem, sem enxergar nada mais para a frente. Sempre foi uma pessoa que teve idéias diferentes, sempre enxergava muito além dos outros, coisas na frente, sabe. Onde estava 
todo mundo olhando para um lado, ele já estava olhando lá para o outro e já estava enxergando mais coisas na frente. [...] Aquela coceira que eu te digo é aquela ansiedade de chegar e estar vendo de que maneira pode fazer melhor, como é que pode fazer melhor. [...] $\mathrm{E}$ ele sempre foi assim uma pessoa inovadora, de perfil inovador. Sempre. Então eu acho que isso aí fez com que a gente também nunca ficasse parado.

22. (T) Cabe salientar que a iniciativa de utilizar o plantio direto partiu do presidente da empresa, o sr. Eurico, a partir do ano de 1985. Este senhor é que impulsionou, dentro do Estado do Rio Grande do Sul, a mudança de paradigma relativamente à forma de cultivar $\mathrm{o}$ arroz irrigado; portanto os produtores que hoje adotam essa tecnologia são apenas os seguidores daquele líder.

23. Eu sou superpositivo nesse sentido. Eu acho, assim, que a crise que a gente viveu nos últimos anos foi a coisa que mais facilitou para que hoje eu tivesse toda a convicção que eu tenho nas coisas que eu acredito fazer. É ter convicção que é só ir botando um tijolinho em cima do outro, que vai dar certo, tranquiilamente!

\section{Novas Oportunidades de Negócio}

24. A gente nunca olhou isso como negócio. A gente achava que era uma filosofia de trabalho. Economizar, gerenciar melhor os meios de produção, racionalizar a utilização do trator, da máquina: era toda uma filosofia de trabalho natural da gente como profissional, como produtor. $\mathbf{E}$, de repente, isto começou a aparecer como sendo uma possibilidade de negócio. Daqui há pouco começou a aparecer aqui um produto que não levava agrotóxico e que tinha valor. $E$ aí a gente começou a prestar atenção nisto. Olha, isso passa a ser um negócio!

25. [...] e talvez este seja o objetivo mais importante, mas é mais de médio e longo prazo. Então, a gente tem essa idéia do arroz como sendo assim ofastfood do arroz, o restaurante do arroz. É como sonha o meu sogro, em ter um restaurante em Porto Alegre. E eu, particularmente, digo para ele: o senhor faz o restaurante e eu sou o fornecedor. Eu vou dar um jeito de ter tudo o que é tipo de arroz, de usar tudo o que é tipo de processo de fabricação que tiver, para agregar valor nesse negócio. E sempre usar o arroz limpo, o arroz certificado, o arroz ISO 14000 , o arroz com selo verde. Não sei, qualquer um desses selos assim que, tranquiilamente, a gente vai ter condições de ter.

26. É aí, então, que nós estamos procurando máquinas para fazer biscoitos de arroz, bolachinhas de arroz. Nós estamos bolando para ter a marca própria do arroz Cerro do Tigre. Provavelmente vai ser esse o nome. Então, nós 
vamos estar no mercado também. Vamos continuar sendo fornecedores da Éffem, continuar fornecendo para a Coolméia, mas vamos ter a marca própria. Inclusive, a idéia de fazer esse negócio aqui é porque nós estamos com idéia de fundar uma cooperativa. Já está tudo organizado para fundarmos uma cooperativa, a Cootigre.

27. Para nós, hoje, a nova oportunidade de negócio é mesmo o agroecoturismo. Pela propriedade, como ela já tem toda essa característica de estar integrada, ela vai despertar o interesse e também pelas belezas naturais que fazem parte dela. Eu acho que estou vislumbrando isto como nova oportunidade.

28. Esse sistema de transplante de mudas eu digo assim: ele é um pouco mais caro do que o pré-germinado. $\mathrm{O}$ investimento que a gente está fazendo e o risco que a gente está correndo é exatamente porque, em vez de nós produzirmos arroz para a indústria, nós vamos produzir semente. E a semente tem um sobrepreço de 40 a $50 \%$ em relação ao arroz.

\section{Notas}

${ }^{1}$ Produção Mais Limpa (PML) é a "aplicação continuada de uma estratégia ambiental preventiva e integrada aos processos, produtos e serviços, a fim de aumentar a eficiência e reduzir os riscos para os homens e o meio ambiente" (UNIDO/UNEP, 1995, p. 4).

${ }^{2}$ Os terceiros, ou também, stakeholders, são quaisquer indivíduos ou grupos que tenham interesse em saber sobre o desempenho de um negócio, incluindo os acionistas, os empregados, os clientes, a comunidade e outras partes que possam ser afetadas (Fiksel, 1996).

\section{RefERENCIAS BibLIOGRÁficas}

BRITO, M. J.;

CARIN, M. M.

Organização, gestão e desempenho ambiental : um estudo de caso. In: XX ENCONTRO ANUAL DA ANPAD (1996 : Angra dos Reis). Anais... Rio de Janeiro : ANPAD, 1996.
CORNELY, S. A.

Introdução à ecologia social. Veritas, v. 37, n. 148, p. 663-671, dez. 1992.

DONAIRE, D.

Gestão ambiental na empresa. São Paulo : Atlas, 1995. 
FERRAZ, J. C.;

KUPFER, D.;

HAGUENAUER, L.

Made in Brazil : desafios competitivos para a indústria. Rio de Janeiro : Campus, 1995.

FERREIRA, A. B. DE H.

Dicionário aurélio eletrônico. São Paulo : Nova Fronteira, 1994.

FIKSEL, J. (Ed.).

Design for environment : creating eco-efficient products and processes. New York : McGrawHill, 1996.

HAMEL, G.;

PRAHALAD, C. K.

Competindo pelo futuro: estratégias inovadoras para obter o controle do seu setor e criar os mercados de amanhã. Rio de Janeiro : Campus, 1995.

Seeing the future first. Fortune, p. 64-68, Set. 1994.

HARTMAN, C. L.;

STAFFORD, E. R.

Market-based environmentalism : developing green marketing strategies and relationships. American Marketing Association, p. 156-163, Winter 1997.

HEILBRONER, R. L.

A história do pensamento econômico. São Paulo : Nova Cultural, 1996.
HUNT, C. B.;

AUSTER, E. R.

Proactive environmental management : avoiding the toxic trap. Sloan Management Review, p. 07-18, Winter 1990.

KNIGHT, F. H.

Risco, incerteza e lucro. Rio de Janeiro : Expressão e Cultura, 1972.

KOTLER, P.

Administração de marketing : análise, planejamento, implementação e controle. 2. ed. São Paulo : Atlas, 1991.

MACHIAVEL, N.

O príncipe. São Paulo : Martins Fontes, 1990.

MAIMON, D.

Eco-estratégia nas empresas brasileiras : realidade ou discurso? Revista de Administração de Empresas, v. 34, n.4, p. 119-130, jul./ago. 1994.

NELSON, R.;

WINTER, S.

An evolutionary theory of economic change. Cambridge : The Belknap Press, 1982.

PAULI, G.

Emissão zero : a busca de novos paradigmas - o que os negócios podem oferecer à sociedade. Porto Alegre : EDIPUCRS, 1996. 
PORTER, M. E.

Competitive advantage. New

York : Free Press, 1985.

Towards a dynamic theory of strategy. Strategic Management Journal, v. 12, p. 95-117, 1991.

PORTER, M. E.;

LINDE, C. V. D.

Green and competitive : ending the stalemate. Harvard Business Review, p. 120-134, Sept./Oct. 1995.

RODRIGUES, R.

$\mathrm{O}$ meio ambiente e o comércio mundial de produtos agrícolas. In: XXX CONGRESSO DE COOPERATIVISMO (1992 : Tóquio). Anais... Tóquio : Aliança Cooperativa Internacional, 1992.

SCHUMPETER, J. A.

A teoria do desenvolvimento econômico. São Paulo : Editora Abril, 1982.
SEBRAE et al.

Gestão ambiental : compromisso da empresa. São Paulo : 1996. n. 1-8.

STEVENSON, H. H;

JARILLO, J. C.

A paradigm of entrepreneurship : entrepreneurial management. Strategic Management Journal, v. 11, p. 17-27, Summer 1990.

THOMPSON, A.

Tomada de decisões sob condições de certeza, risco e incerteza. Porto Alegre : FCE/Departamento de Economia, 1995. n. 6.

\section{UNIDO/UNEP.}

Cleaner production assesment manual. Draft, 1995. part one: introduction to cleaner production.

ZAWISLAK, P. A.

Notas de aula da disciplina Economia da Inovação Tecnológica do PPGA/UFPR, Porto Alegre 1996. 